Petros Ismailidis ORCID iD: 0000-0003-1551-7902

Annegret Mündermann ORCID iD: 0000-0002-6472-1689

Corina Nüesch ORCID iD: 0000-0002-7526-9536

\title{
Kinematic changes in severe hip osteoarthritis measured at matched gait speeds
}

Petros Ismailidiss,b,c, Mara Kaufmann ${ }^{\mathrm{a}}$, Martin Clauss ${ }^{\mathrm{a}}$, Geert Pagenstert ${ }^{\mathrm{b}, \mathrm{e}}$, Anke Eckardt $^{f}$, Thomas Ilchmann ${ }^{\mathrm{f}}$, Annegret Mündermann ${ }^{\mathrm{a}, \mathrm{b}, \mathrm{c}, \mathrm{d}}$, Corina Nüesch ${ }^{\mathrm{a}, \mathrm{b}, \mathrm{c}, \mathrm{d}}$

${ }^{\mathrm{a}}$ Department of Orthopaedics and Traumatology, University Hospital Basel, Basel,

Switzerland

${ }^{\mathrm{b}}$ Department of Clinical Research, University of Basel, Basel, Switzerland

${ }^{c}$ Department of Biomedical Engineering, University of Basel, Basel, Switzerland

${ }^{\mathrm{d}}$ Department of Spine Surgery, University Hospital Basel, Basel, Switzerland

${ }^{\text {e }}$ Clarahof Clinic of Orthopaedic Surgery, Clarahofweg 19a, 4058 Basel, Switzerland

${ }^{\mathrm{f}}$ ENDO-Team, Hirslanden Klinik, Birshof, Reinacherstrasse 28, 4142 Münchenstein,

Switzerland

Original Research Article

August 2020

Submitted to: Journal of Orthopaedic Research

Manuscript \# JOR-20-0299

Address of correspondence: Dr. Petros Ismailidis

Department of Orthopaedics and Traumatology

University Hospital Basel

Spitalstrasse 21

4031 Basel, Switzerland

Tel. +41 789490281,Fax + 41612657829

Email petrosismailidis@gmail.com

Running Title: Matched Speed Hip OA Kinematics

CRediT authorship contribution statement

Petros Ismailidis: Conceptualization, Investigation, Data Curation, Writing - Original Draft, Funding acquisition; Mara Kaufmann: Investigation, Writing - Review \&

Editing; Martin Clauss: Resources, Provision of study patients, Writing - Review \& Editing; Geert Pagenstert Resources, Provision of study patients, Writing - Review \& Editing; Anke Eckardt: Resources, Provision of study patients, Writing - Review \& Editing; Thomas Ilchmann Resources, Provision of study patients, Writing Review \& Editing; Annegret Mündermann: Conceptualization, Methodology, Validation, Formal analysis, Resources, Writing - Review \& Editing, Supervision, Project administration. Corina Nüesch: Conceptualization, Methodology, Validation, Formal analysis, Resources, Writing - Review \& Editing, Supervision, Project administration;

This article has been accepted for publication and undergone full peer review but has not been through the copyediting, typesetting, pagination and proofreading process, which may lead to differences between this version and the Version of Record. Please cite this article as doi: $10.1002 /$ jor.24858.

This article is protected by copyright. All rights reserved. 


\begin{abstract}
Kinematic differences between patients with osteoarthritis (OA) and control participants have been reported to be influenced by gait speed. The purpose of this study was to experimentally detect the effect of walking speed on differences in spatiotemporal parameters and kinematic trajectories between patients with hip OA and age matched asymptomatic participants using wearable sensors and statistical parametric mapping (SPM). Twenty-four patients with severe unilateral hip OA and 48 control participants were included in this study. Patients walked at a self-selected normal speed and control participants at self-selected normal and slow speeds. Spatiotemporal parameters and kinematic trajectories were measured with the inertial sensor system Rehagait ${ }^{\circledR}$. Gait parameters were compared between patients with hip OA and control participants for normal and matched speed using SPM with independent sample t tests. At self-selected normal speed, the patient group walked slower $(-0.20 \mathrm{~m} / \mathrm{s}, \mathrm{P}<0.001)$ and at lower cadence $(-5.0$ steps/minute, $\mathrm{P}<0.001)$ as well as with smaller hip flexion $\left(-7.4^{\circ}, \mathrm{P}<0.001\right)$ and extension $\left(-4.1^{\circ}, \mathrm{P}=0.001\right)$, higher knee flexion during terminal stance $\left(+8.0^{\circ}, \mathrm{P}<0.001\right)$ and higher ankle dorsiflexion and plantarflexion $\left(+7.1^{\circ}, \mathrm{P}<0.001\right)$. While differences in spatiotemporal parameters and the ankle trajectory disappeared at matched speed, some clinically relevant and statistically significant differences in hip and knee trajectories remained. Most differences in sagittal plane gait kinematics between patients with hip OA and control participants were present for matched speed, and therefore appear to be associated with disease rather than gait speed. Nevertheless, studies investigating hip kinematics in patients with hip OA should involve trials at matched speeds.
\end{abstract}

This article is protected by copyright. All rights reserved. 


\section{Key words:}

Kinematics; hip osteoarthritis; matched speeds; inertial sensors; gait analysis

\section{Introduction}

Gait analysis as a way to investigate hip osteoarthritis (OA) has been long recognized. ${ }^{1}$ Understanding the effects of OA on gait could help to promptly diagnose initial stages of the disease, develop physiotherapy protocols and surgical treatments as well as evaluate the results of these treatments. ${ }^{2}$ Therefore, many studies have tried to identify parameters that adequately describe gait in patients with hip OA. ${ }^{1,3}$ Yet, gait analysis has not been established as a measure for planning and evaluating treatment strategies in patients with hip OA and suitable kinematic markers describing hip OA have not been defined. ${ }^{2}$

One possible reason is the complexity of the measurements as most studies are performed with camera-based systems in dedicated laboratories. ${ }^{1,3}$ In recent years, wearable inertial sensors have emerged as an inexpensive, time efficient and practical way to perform gait analysis. ${ }^{4}$ Consequently, they could help reduce the resources needed for gait analysis and hence allow studies to include larger samples of patients.

Most previous gait studies describe gait patterns using discrete kinematic parameters. ${ }^{1}$ However, because gait is a continuous process, methods examining the entire gait cycle rather than isolated parameters seem more appropriate for detecting kinematic differences. To overcome this problem, statistical parametric mapping (SPM) has been applied as a statistical method allowing the examination of continuous dynamic information of gait data. SPM has been successfully applied to analyse kinematic gait data in healthy participants ${ }^{5}$ and in patients with knee $\mathrm{OA}^{6}$ or hip OA. ${ }^{2}$

This article is protected by copyright. All rights reserved. 
Patients with hip OA have been shown to have slower self-selected walking speeds compared to control participants. ${ }^{3}$ Walking speed has been shown to affect gait parameters in healthy participants ${ }^{7}$, patients with knee $\mathrm{OA}^{6,8}$ and patients with hip OA. ${ }^{9}$ Therefore, concerns have been raised that the measured kinematic differences could be a result of the altered speed and not of disease specific joint biomechanics. These concerns have mainly been discussed for knee $\mathrm{OA}^{10}$ and less for hip OA. Statistical ways to account for differences in walking speed ${ }^{8}$ applied in knee OA have been criticized as incorrect. ${ }^{10}$ To overcome the problem of speed as a confounding factor in kinematics of hip OA, other research groups have tried to capture measurements at matched walking speeds mainly by letting patients and control participants walk at preselected speeds on a treadmill ${ }^{9,11,12}$ or at self-selected slow, normal and fast walking speeds in a gait laboratory. ${ }^{2}$ However, especially in patients, gait patterns captured at preselected walking speeds and in a laboratory environment may not represent their habitual (compensatory) gait patterns. We propose that disease specific gait patterns in patients with hip OA should be assessed at patients' preferred walking speed (also outside of the laboratory) and that walking trials of healthy control participants at a slow self-selected walking speed (matching that of patients) should be used for comparing gait patterns between patient and control groups.

The purpose of this study was to experimentally detect the effect of walking speed on differences in spatiotemporal parameters and kinematic trajectories between patients with hip OA and age matched asymptomatic control participants. The first aim was to describe differences in spatiotemporal parameters and kinematic trajectories assessed using a wearable sensor system at self-selected normal walking speed between patients with hip OA and age control participants by examining continuous kinematic trajectories with SPM. The second aim was to determine if these 
differences persist when trials of control participants at walking speed matched to that of patients were selected that were obtained in gait tests at normal and slow selfselected walking speed.

\section{Methods}

Level of evidence: III, case-control study.

ClinicalTrials.gov Identifier: NCT03860610

\section{Study population}

Twenty-four patients with severe unilateral hip OA scheduled for a total hip arthroplasty and 48 age matched asymptomatic control participants were included in this study. The inclusion and exclusion criteria are listed in Table 1, and the demographic parameters of each group are described in Table 2. All participants gave written informed consent prior to participation. This study was approved by the regional review board and conducted in accordance with the Declaration of Helsinki.

\section{Clinical and radiological evaluation}

The function and symptoms of the patients and control participants were evaluated with the HOOS score. ${ }^{13}$ The HOOS score consists of 40 questions divided in five subcategories. Each subcategory is evaluated separately, 100 being the best possible score. The radiographic severity of the OA of the affected hip in patients was graded according to the Kellgren/Lawrence (K/L) radiographic severity scale. ${ }^{14}$ Osteoarthritis K/L grade I was accepted on the unaffected side as long as there were no symptoms. The control participants were not assessed radiologically because of ethical reasons to avoid unnecessary radiation.

This article is protected by copyright. All rights reserved. 
Gait analysis

Gait analysis was performed with the RehaGait ${ }^{\circledR}$ (Hasomed GmbH, Magdeburg, Germany) wearable sensor system that uses seven inertial sensors placed on the pelvis (overlying the $5^{\text {th }}$ lumbar vertebra) and bilaterally on the feet, shank, thigh. ${ }^{6,15}$ For OA patients, data for two walking trials at a self-selected speed for 20 meters in a flat corridor were recorded. Control participants performed four trials: two trials of walking at normal followed by two trials at slow self-selected speed because it was important to capture the participants habitual gait pattern first without the participant being conscious about the walking speed. In each trial, data for 10 left and 10 right steps were captured. For each participant and condition, only the second trial was considered in the analysis. Spatiotemporal parameters as well as sagittal plane hip, knee and ankle angles were calculated by the manufacturer's software (Hasomed GmbH, Magdeburg, Germany) and exported for further analysis. Calculations were based on published algorithms that incorporate accelerometer and gyroscope data to calculate joint angles between sensors mounted on adjacent segments. ${ }^{16}$ The neutral position was defined in each trial from the static position before each gait trial. The system has been shown to be repeatable and measure comparable sagittal joint angles compared to a marker-based system. ${ }^{15}$ After exporting, data were time normalized to consecutive heel strikes of the same foot defining a gait cycle. Ensemble means for each parameter and kinematic trajectory were computed across all steps for each participant and, in case of control participants, for each speed using Matlab (MathWorks Inc., Natick, MA, USA).

This article is protected by copyright. All rights reserved. 


\section{Statistical Analysis}

The necessary sample size estimation was performed according to group differences reported in the literature. ${ }^{17}$ Nine participants would be required to detect an expected difference in hip range of motion (ROM) with an effect size of at least 1.33 with $80 \%$ power at a $5 \%$ significance level. Because we assumed that differences between groups at matched speed may be smaller, we then estimated the required samples size for an expected difference in hip ROM for an effect size of 0.9 resulting in 20 required participants to detect a difference with $80 \%$ power at a $5 \%$ significance level. Therefore, we considered recruiting at least 20 participants per group.

A data set of matched walking speeds was generated by matching each patient to one trial from the control group (from either speed condition) with minimal difference in walking speed. Data for any given control participant could only be entered once. In case of more than one possibility, preference was given to trials at self-selected speed. Statistical analysis was then performed at two levels: firstly, comparing spatiotemporal and kinematic data of patients with hip OA with those of all control participants $(\mathrm{N}=48)$ at self-selected normal speed, and secondly comparing spatiotemporal and kinematic data of patients with hip OA with those of a subset of trials of control participants at matched speed (matched speed subgroup; $\mathrm{N}=24$ ).

For spatiotemporal parameters, we calculated 95\% confidence intervals of group differences. In addition, independent sample t-tests were performed to detect statistically significant differences between groups. The significance level was set a priori to 0.05 with a Bonferroni correction to account for multiple comparisons resulting in a significance level of 0.025 . All statistical analyses of spatiotemporal parameters were performed in SPSS Version 22 (IBM Corporation, Amonk, NY, 
USA). For sagittal joint angle trajectories, we performed independent sample t tests using SPM as described by Pataky. ${ }^{18}$ SPM performs statistical tests on entire time series and the null hypothesis of no differences between groups is rejected when the computed t-value exceeds the critical threshold which is calculated based on Gaussian random field theory. The significance level for all statistical tests of the SPM analysis was adjusted for multiple comparison and set a priori to 0.025 . Additionally, mean differences in the joint angles were calculated by subtracting the mean of the control group from the mean of the patient group. All SPM analyses were performed using Matlab (MathWorks Inc., Natick, MA, USA) with the SPM toolbox (www.spm1d.org). For patients, we only considered parameters of the affected side. Spatiotemporal or kinematic parameters did not differ between the two legs of the control group ( $>>0.678)$. Therefore, the left side of all control participants was used for all comparisons.

\section{Results}

Participant characteristics and clinical evaluation

The demographic characteristics, HOOS scores and K/L scores are presented in Table 2. Of all demographic parameters, only body mass and BMI differed between patients and asymptomatic controls, but this difference disappeared for the matched speed subgroup of controls (Table 2). The HOOS scores were significantly lower in the patient group than in the control group for each subcategory $(\mathrm{P}<0.001$, HOOS Pain -46.3, HOOS Symptoms -49.0, HOOS ADL -44.8, HOOS Sport/Rec -62.9, HOOS QOL -69.9). 


\section{Spatiotemporal parameters}

Self-selected normal speed. The patient group walked on average at a slower walking speed $(-0.20 \mathrm{~m} / \mathrm{s}, \mathrm{P}<0.001)$ and with a lower cadence $(-5.0$ steps/minute, $\mathrm{P}<0.001)$ than the control group. Furthermore, the single support phase expressed as percentage of the gait cycle in the affected side in patients with hip OA was significantly shorter $(-3 \%, \mathrm{P}<0.001)$ than in the control group (Table 3$)$.

Matched speed. For eight patients, the control participants with matched speed walked at slow speed, and for 12 patients at self-selected walking speed. Walking speed of the patient group and the matched speed subgroup was comparable (mean difference: $0.01 \pm 0.05 \mathrm{~m} / \mathrm{s}, \mathrm{P}=0.875$ ) with a maximum difference of $0.04 \mathrm{~m} / \mathrm{s}$ except for one very slow walking patient (difference of $0.25 \mathrm{~m} / \mathrm{s}$ ). Cadence, stride length and stride duration did not differ between groups (Table 3).

\section{Sagittal joint angles}

Self-selected normal speed. Hip flexion angles during stance (0-30\% gait cycle, maximum $\left.-7.4 \pm 5.7^{\circ}, \mathrm{P}<0.001\right)$ and during swing (72-100\% gait cycle, maximum $8.9 \pm 6.1^{\circ}, \mathrm{P}<0.001$ ) were significantly smaller in the hip OA group compared to the control group. Hip extension angles during terminal stance (42-59\% gait cycle, maximum $-4.1 \pm 2.9^{\circ}, \mathrm{P}=0.001$ ) were significantly smaller in the hip OA group compared to the control group. Knee flexion angles during terminal stance (34-53\% gait cycle, maximum $+8.0 \pm 5.5^{\circ}, \mathrm{P}<0.001$ ) were significantly greater in the hip $\mathrm{OA}$ group compared to the control group. Furthermore, the ankle was more dorsiflexed during the second half of the stance and early swing phase (29-67\% gait cycle, 
maximum $+7.1 \pm 7.6^{\circ}, \mathrm{P}<0.001$ ) in the hip OA group compared to the control group (Figure 1).

Matched speed. Compared to the matched speed subgroup, patients with hip OA had less hip flexion during early stance and terminal swing (13-27 \% gait cycle, maximum $-4.9 \pm 5.3^{\circ}, \mathrm{P}=0.002 ; 88-95 \%$ gait cycle, maximum $\left.-6.7 \pm 6.4^{\circ}, \mathrm{P}=0.014\right)$ and less hip extension during terminal stance (49-60 \% gait cycle, maximum $-4.2 \pm 3.1^{\circ}, \mathrm{P}=0.006$ ), as well as greater knee flexion during terminal stance (36-57 \% gait cycle, maximum $\left.9.9 \pm 8.0^{\circ}, \mathrm{P}<0.001\right)$. There were no statistically significant differences in the ankle kinematics (Figure 2).

\section{Discussion}

In this study, we experimentally investigated the effect of walking speed on differences in spatiotemporal parameters and kinematic trajectories between patients with hip OA and control participants using a wearable sensor system and SPM analysis. Spatiotemporal differences were not present at matched speed conditions. While similar kinematic differences in hip and knee kinematics were detected at both speeds, the part of the gait cycle in which these differences were statistically significant as well as the magnitude of the differences were not identical. These results have important clinical applications on the way measured differences in gait kinematics between groups and within participants are interpreted.

The relevance of the gait speed influence on kinematics has been recognized for healthy individuals ${ }^{7}$ and patients with knee OA. ${ }^{6,8}$ The same influence has been suspected for patients with hip OA, and few studies were performed to investigate the influence of gait speed on spatiotemporal and kinematic changes characterizing hip OA. ${ }^{2,9,11,12}$ Different scientific approaches have been used to address this question. For 
instance, Kiss ${ }^{12}$, Möckel et al. ${ }^{9}$ and Bejek et al. ${ }^{11}$ performed gait analysis on a treadmill with predefined speeds. This method has the advantage that patients and controls can be completely matched for speed. However, because OA is an age related disease, the patient samples of studies investigating OA is expected to involve geriatric patients. ${ }^{19}$ The mean age of the patients at the study of Kiss (2010) was 71.5 \pm 3.4 years (moderate OA) and $70.8 \pm 2.7$ years (severe OA), in the study of Möckel et al. (2003) $64.8 \pm 7.51$ years and in the study of Bejek et al. (2006) $69.7 \pm 8.9$ years. In this age group and in patients with hip OA, one cannot expect that all patients will be able to comfortably walk on a treadmill without any support or sufficient practice. Therefore, these studies unavoidably only investigate a particular subgroup of patients with hip OA. Not surprisingly, less than half of the patients with hip OA included in the study of Bejek et al. ${ }^{11}$ were able to perform the trial at the fast speed $(1.1 \mathrm{~m} / \mathrm{s})$.

Furthermore, although the exact influence of treadmill walking on gait kinematics in patients with OA is not known, healthy participants have been reported to have altered kinematics when walking on a treadmill. ${ }^{20}$ While studies on healthy participants reported significant but small differences in peak joint angles between overground and treadmill walking (average difference, $\left.<3^{\circ}\right)^{21,22}$, such differences may be greater in patients who are less experienced with treadmill walking. Consequently, the differences measured with this method could diverge from overground kinematics. Ardestani and Wimmer ${ }^{2}$ addressed this problem by letting the patients walk in a laboratory at self-selected slow, normal and fast walking speeds. While this technique is more appropriate, it could cause discomfort in patients with hip OA when asked to walk at a fast speed and data for only few steps can be recorded. In our study, the patient group was only asked to complete two trials at a self-selected normal speed.

This article is protected by copyright. All rights reserved. 
Appropriate trials were selected from the control group in order to create a speedmatched subgroup.

Regarding spatiotemporal parameters, we measured lower walking speed and cadence as well as a lower single support phase for the affected side of the OA group. Our findings at self-selected speed are in clear accordance with the literature confirmed by a systematic review. ${ }^{3}$ According to our measurements, differences between patients and controls in all spatiotemporal parameters disappeared in matched speed conditions. These results agree with Möckel et al. ${ }^{9}$ who found similar values for spatiotemporal parameters at matched speed and advised against comparing spatiotemporal parameters without controlling for walking speed because of the speed dependency of these parameters. However, Bejek et al. ${ }^{11}$ found cadence to be higher and step length to be lower in patients with OA. Unfortunately, the only study not performing the measurements on a treadmill ${ }^{2}$ did not report spatiotemporal data, and Kiss ${ }^{12}$ measured spatiotemporal parameters but did not report absolute values but only standard deviations as a sign of asymmetry. Altogether, the presence of spatiotemporal differences at matched speeds has only been investigated by three studies, including the present one, with different results regarding cadence and step length.

In the present study, at self-selected speeds the hip OA group had lower hip flexion and extension angles during stance and swing, greater knee flexion during terminal stance as well as higher ankle dorsiflexion during terminal stance and lower plantarflexion during initial swing. These hip and knee kinematic differences were also present at matched speeds. Several studies measuring discrete parameters have reported lower hip and knee ROM at self-selected speeds in patients at different stages of hip OA. ${ }^{8,17,23}$ Ardestani and Wimmer ${ }^{2}$ also used SPM analysis and found the same This article is protected by copyright. All rights reserved. 
differences in hip, knee and ankle kinematics as in our study for self-selected speeds. For matched speeds, they reported that only the hip flexion angles remained significantly lower. Only few other studies provided data on differences in gait trajectories between patients with hip OA and control participants. While Bejek et al. ${ }^{11}$ measured discrete parameters and reported differences in hip and knee ROM at all matched speeds, they did not perform measurements at self-selected speeds. Similarly, Möckel et al. ${ }^{9}$ performed measurements at three different speeds and found knee and hip flexion and extension to be lower in patients with hip OA than in controls. However, because the latter three studies only performed measurements at predefined speeds, it is not possible to conclude which of these changes would be present at self-selected speeds. Furthermore, information for ankle kinematics was not reported by these studies.

The strengths of this study include the ability to capture trials with matched speeds in a patient and healthy group with comparable demographic characteristics. The size of the control group was large enough to allow selecting matched speed trials without having to force the patients to walk in a faster, unnatural way or at a fixed speed on a treadmill. The analysis of a subgroup of trials for control participants at matched speed indicated the potential role of the choice of control participants. This is particularly relevant as most studies compare gait patterns of patients with hip OA to those of convenience samples of control participants without regarding the walking speed as confounding parameter where this choice could affect the respective study results. We cannot preclude that walking slower may be less familiar for control participants and hence affect gait. In this study we assumed that walking slower than normal will have a smaller effect on gait in healthy participants than walking faster may have in patients with hip OA and pain. The patient group included only 
participants with severe hip OA and was therefore homogenous. Larger studies involving patients with different disease stages are needed to identify parameters that are able to detect early disease stages. Radiographs of the control group were not performed and therefore mild asymptomatic OA cannot be ruled out. Moreover, the measurements took place on a single day for each patient and therefore day to day variability cannot be excluded. The RehaGait ${ }^{\circledR}$ system uses the static position before the start of each walking trial as reference position. Similarly, camera-based methods use a static trial as reference trial for defining the joint coordinate systems. This position may not in all participants correspond to the anatomical neutral hip position. However, while this can affect the absolute differences in the hip trajectories, our results show that both maximum hip flexion and extension were smaller in hip OA patients, indicating that the hip ROM is reduced in patients.

In summary, this study adds to the limited existing literature investigating the influence of walking speed of controls on the comparison of sagittal plane kinematics between patients with hip OA and control participants. We suggest different methodological approaches to perform the gait analysis, attain matched speed trials, and perform statistical analysis over the entire gait cycle. In patients with hip OA, lower hip and knee ROM seem to be primarily a consequence of the altered joint biomechanics and not a result of slower gait speed. However, there is some inconsistency between our results and previous studies regarding which spatiotemporal and kinematic parameters are only a result of the walking speed. It is important to find ways to analyse trials collected at the same speed without compromising the natural (compensatory) gait pattern in patients. Involving a larger sample of control participants should provide enough trials to facilitate matched speed 
comparisons. The usage of inertial sensors significantly reduces the use of resources needed for gait analysis, hence making larger studies feasible.

\section{Conclusions}

Changes of the hip and knee kinematics in patients with hip OA remain significant in matched speed conditions. However, because the magnitude of the differences is not identical, performing measurements at matched speeds should be included in studies examining kinematics in hip OA. Moreover, the use of inertial sensors for assessing gait in hip OA could help increase the sample size of gait studies, hence providing data for performing speed matched comparisons and explore the potential of using kinematic parameters as functional outcomes in clinical trials.

\section{Acknowledgements:}

Funding was received from the Department of Orthopaedics and Traumatology and the Department of Surgery of the University of Basel, Swiss Orthopaedics, Merian Iselin Foundation and Deutsche Arthrose-Hilfe e.V. The funding sources had no involvement in any aspect of this study.

\section{References}

1. Ornetti, P, Maillefert, JF, Laroche, D, et al. 2010. Gait analysis as a quantifiable outcome measure in hip or knee osteoarthritis: a systematic review. Joint Bone Spine 77: 421-425.

2. Ardestani, MM, Wimmer, MA. 2016. Can a linear combination of gait principal component vectors identify hip OA stages? J Biomech 49: 2023-2030.

3. Constantinou, M, Barrett, R, Brown, M, Mills, P. 2014. Spatial-temporal gait characteristics in individuals with hip osteoarthritis: a systematic literature review and meta-analysis. J Orthop Sports Phys Ther 44: 291-B297.

This article is protected by copyright. All rights reserved. 
4. Caldas, R, Mundt, M, Potthast, W, et al. 2017. A systematic review of gait analysis methods based on inertial sensors and adaptive algorithms. Gait Posture 57: 204-210.

5. Nüesch, C, Roos, E, Egloff, C, et al. 2019. The effect of different running shoes on treadmill running mechanics and muscle activity assessed using statistical parametric mapping (SPM). Gait and Posture 69: 1-7.

6. Ismailidis, P, Egloff, C, Hegglin, L, et al. 2020. Kinematic changes in patients with severe knee osteoarthritis are a result of reduced walking speed rather than disease severity Gait Posture 79: 256-261.

7. Fukuchi, CA, Fukuchi, RK, Duarte, M. 2019. Effects of walking speed on gait biomechanics in healthy participants: a systematic review and meta-analysis. Syst Rev 8: 153.

8. Zeni, JA, Jr., Higginson, JS. 2009. Differences in gait parameters between healthy subjects and persons with moderate and severe knee osteoarthritis: a result of altered walking speed? Clin Biomech (Bristol, Avon) 24: 372-378.

9. Mockel, G, Perka, C, Labs, K, Duda, G. 2003. The influence of walking speed on kinetic and kinematic parameters in patients with osteoarthritis of the hip using a force-instrumented treadmill and standardised gait speeds. Arch Orthop Trauma Surg 123: 278-282.

10. Astephen Wilson, JL. 2012. Challenges in dealing with walking speed in knee osteoarthritis gait analyses. Clin Biomech (Bristol, Avon) 27: 210-212.

11. Bejek, Z, Paroczai, R, Illyes, A, Kiss, RM. 2006. The influence of walking speed on gait parameters in healthy people and in patients with osteoarthritis. Knee Surg Sports Traumatol Arthrosc 14: 612-622.

12. Kiss, RM. 2010. Effect of walking speed and severity of hip osteoarthritis on gait variability. Journal of electromyography and kinesiology: official journal of the International Society of Electrophysiological Kinesiology 20: 1044-1051.

This article is protected by copyright. All rights reserved. 
13. Nilsdotter, AK, Lohmander, LS, Klassbo, M, Roos, EM. 2003. Hip disability and osteoarthritis outcome score (HOOS)--validity and responsiveness in total hip replacement. BMC Musculoskelet Disord 4: 10.

14. Kellgren JH, LJ. 1963. The Epidemiology of Chronic Rheumatism: Atlas of Standard Radiographs of Arthritis. Blackwell Scientific Publications.

15. Nüesch, C, Roos, E, Pagenstert, G, Mündermann, A. 2017. Measuring joint kinematics of treadmill walking and running: Comparison between an inertial sensor based system and a camera-based system. Journal of Biomechanics 57: 32-38.

16. Seel, T, Raisch, J, Schauer, T. 2014. IMU-based joint angle measurement for gait analysis. Sensors (Basel, Switzerland) 14: 6891-6909.

17. Eitzen, I, Fernandes, L, Nordsletten, L, Risberg, MA. 2012. Sagittal plane gait characteristics in hip osteoarthritis patients with mild to moderate symptoms compared to healthy controls: a cross-sectional study. BMC Musculoskelet Disord 13: 258.

18. Pataky, TC. 2012. One-dimensional statistical parametric mapping in Python. Comput Methods Biomech Biomed Engin 15: 295-301.

19. Neogi, T, Zhang, Y. 2013. Epidemiology of osteoarthritis. Rheumatic diseases clinics of North America 39: 1-19.

20. Alton, F, Baldey, L, Caplan, S, Morrissey, MC. 1998. A kinematic comparison of overground and treadmill walking. Clinical biomechanics (Bristol, Avon) 13: 434-440.

21. Riley, PO, Paolini, G, Della Croce, U, et al. 2007. A kinematic and kinetic comparison of overground and treadmill walking in healthy subjects. Gait and Posture 26: 17-24.

22. Parvataneni, K, Ploeg, L, Olney, SJ, Brouwer, B. 2009. Kinematic, kinetic and metabolic parameters of treadmill versus overground walking in healthy older adults. Clinical Biomechanics (Bristol, Avon) 24: 95-100.

This article is protected by copyright. All rights reserved. 
23. Ornetti, P, Laroche, D, Morisset, C, et al. 2011. Three-dimensional kinematics of the lower limbs in hip osteoarthritis during walking. Journal of Back and Musculoskeletal Rehabilitation 24: 201-208.

Figure and Table Legends

Fig. 1. Hip (left), knee (middle) and ankle (right) kinematics in patients with severe hip OA (N=24; red) and asymptomatic control participants ( $\mathrm{N}=48$; black) for walking at normal self-selected speed. Top—-mean and 1 standard deviation of joint angles normalized to one gait cycle; centre-actual t-value (solid line) for independent t-tests determined using statistical parametric mapping and critical value (dashed line) that smooth, 1D multivariate Gaussian data would reach in an infinite number of experiments involving smooth $1 \mathrm{D}$ data $(\mathrm{P}=0.025)$; bottom-difference between mean curves of patients with severe hip OA and the control group (positive values indicate larger values in patients).
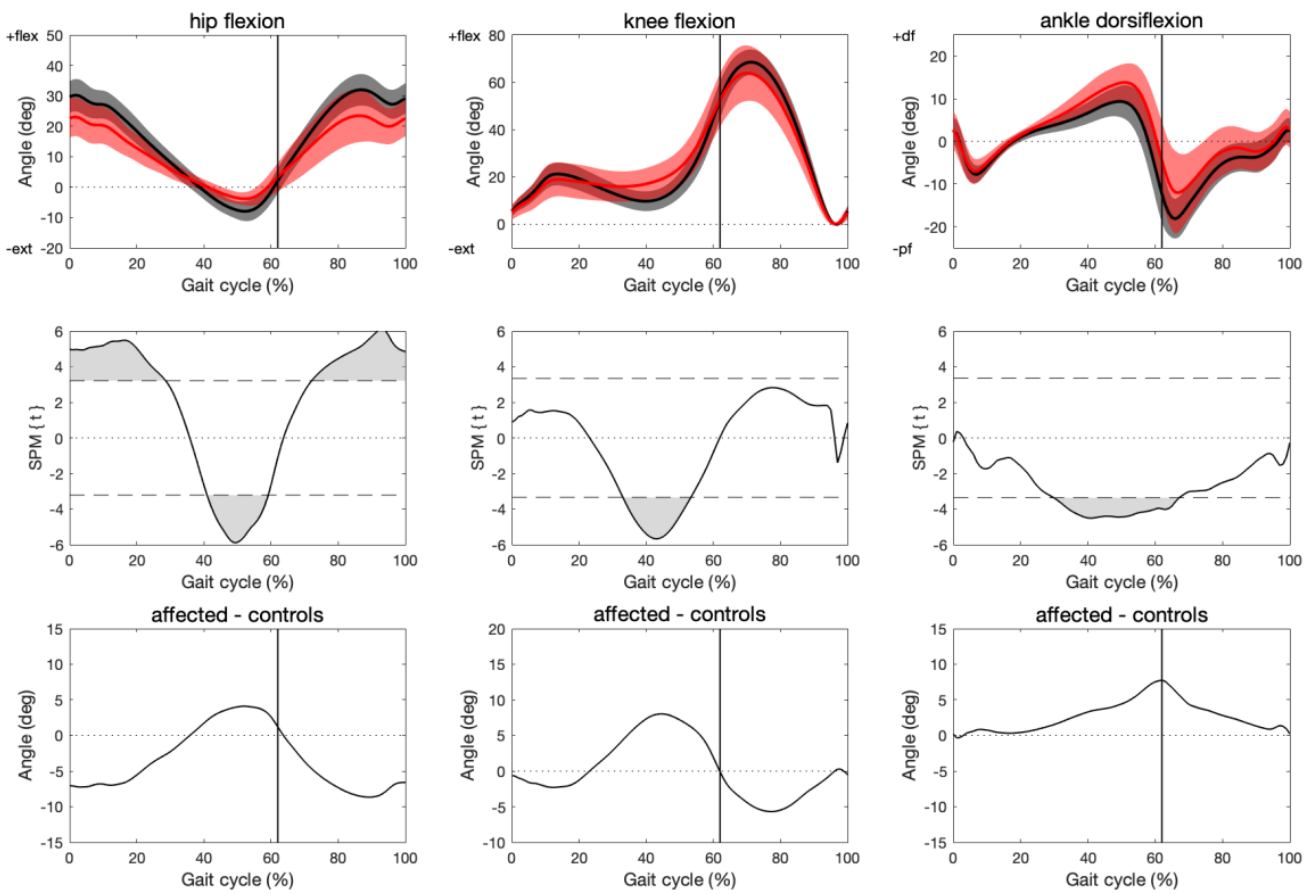

This article is protected by copyright. All rights reserved. 
Fig. 2. Hip (left), knee (middle) and ankle (right) kinematics in trials of patients with severe hip OA ( $\mathrm{N}=24$; red) and trials of asymptomatic control participants at matched speed $(\mathrm{N}=24$; black). Top-mean and 1 standard deviation joint angles normalized to one gait cycle; centre-actual t-value (solid line) for independent t-tests determined using statistical parametric mapping and critical value (dashed line) that smooth, $1 \mathrm{D}$ multivariate Gaussian data would reach in an infinite number of experiments involving smooth $1 \mathrm{D}$ data $(\mathrm{P}=0.025)$; bottom-difference between mean curves of patients with severe hip OA and the control group (positive values indicate larger values in patients).
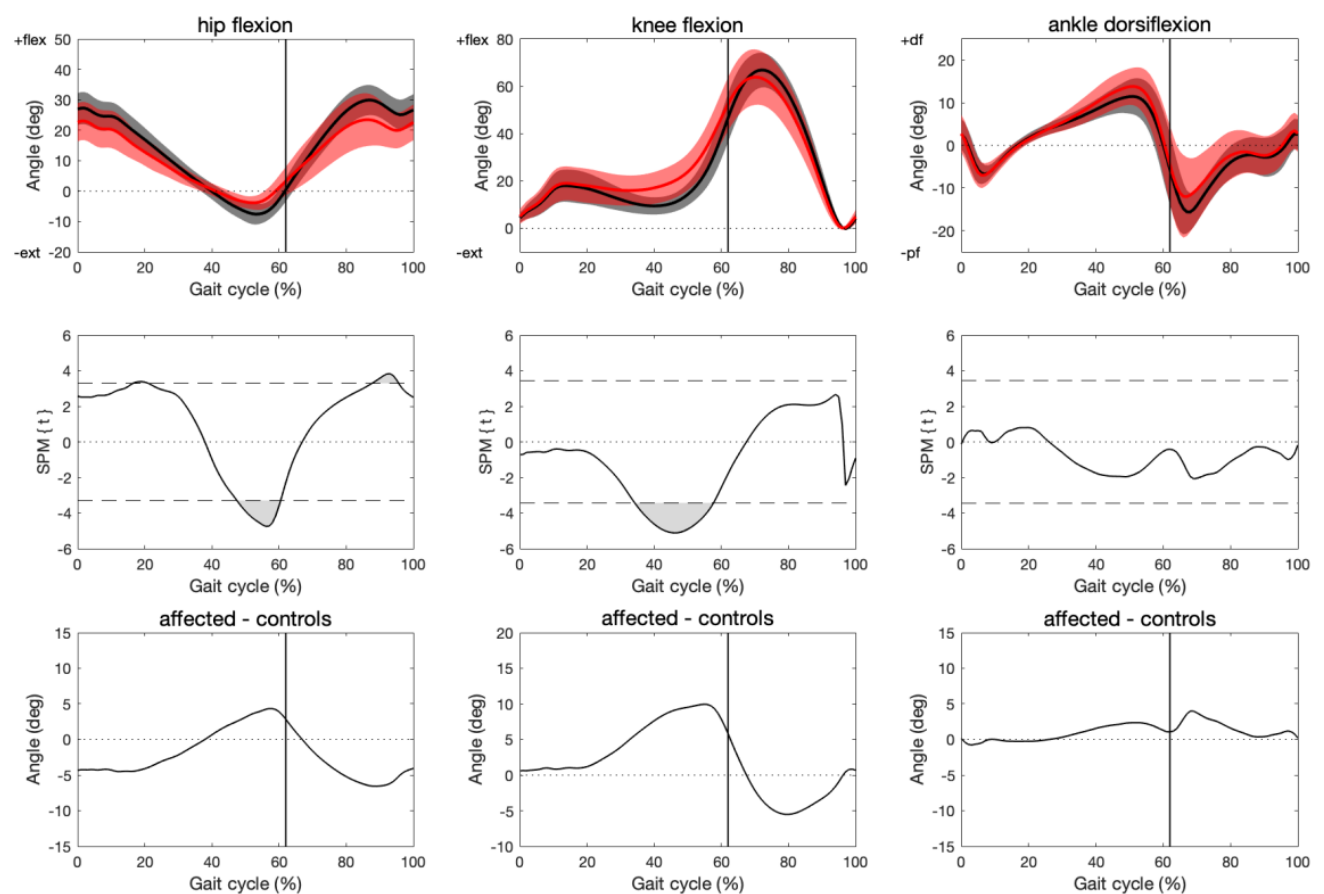

This article is protected by copyright. All rights reserved. 
Table 1: Inclusion and exclusion criteria

\begin{tabular}{|c|c|c|}
\hline & $\begin{array}{l}\text { Patients with severe hip } \\
\text { osteoarthritis }\end{array}$ & Asymptomatic control subjects \\
\hline $\begin{array}{l}\text { Inclusion } \\
\text { criteria }\end{array}$ & $\begin{array}{l}\text { - } \text { age } \geq 30 \text { years } \\
\text { diagnosed unilateral OA of the } \\
\text { hip } \\
\text { radiographic evidence of } \\
\text { contralateral OA grade I K/L } \\
\text { was tolerated } \\
\text { - } \\
\text { patient scheduled for THA }\end{array}$ & $\begin{array}{l}\text { - age } \geq 30 \text { years } \\
\text { no clinical diagnosis of OA, } \\
\text { rheumatoid arthritis } \\
\text { no history of hip or knee trauma } \\
\text { or pain at the time of the } \\
\text { measurement }\end{array}$ \\
\hline $\begin{array}{l}\text { Exclusion } \\
\text { criteria }\end{array}$ & $\begin{array}{ll}\text { - } & \text { BMI }>35 \mathrm{~kg} / \mathrm{m}^{2} \\
\text { - } & \text { use of walking aids } \\
\text { - } & \text { neuromuscular disorders } \\
\text { affecting gait } \\
\text { - } & \text { inability to follow procedures } \\
\text { due to psychological disorders } \\
\text { or dementia }\end{array}$ & $\begin{array}{ll}\text { - } & \text { HOOS }<90 \text { in pain subcategory } \\
\text { - } & \text { BMI }>35 \mathrm{~kg} / \mathrm{m}^{2} \\
\text { - } & \text { use of walking aids } \\
\text { - } & \text { neuromuscular disorders } \\
& \text { affecting gait } \\
\text { - } & \text { inability to follow procedures } \\
\text { due to psychological disorders } \\
\text { or dementia }\end{array}$ \\
\hline
\end{tabular}

OA-osteoarthritis; THA-total hip arthroplasty; BMI-body mass index; HOOS-hip injury and osteoarthritis outcome score

This article is protected by copyright. All rights reserved. 
Table 2. Mean (1 standard deviation) characteristics of patients with hip OA scheduled for total hip replacement $(\mathrm{N}=24)$, age-matched asymptomatic control subjects ( $\mathrm{N}=48)$ and, speed-matched selection subgroup of the asymptomatic control subjects $(\mathrm{N}=24)$

\begin{tabular}{|c|c|c|c|c|c|}
\hline Parameter & $\begin{array}{l}\text { Patients } \\
N=24\end{array}$ & $\begin{array}{l}\text { Asymptomatic } \\
\text { controls } \\
N=48\end{array}$ & $\begin{array}{c}\text { Controls } \\
\text { subgroup } \\
\text { matched } \\
\text { speed } N=24\end{array}$ & $\begin{array}{l}\text { P value } \\
\text { (patients - } \\
\text { controls) }\end{array}$ & $\begin{array}{l}\text { P value } \\
\text { (patients - } \\
\text { subgroup } \\
\text { matched } \\
\text { speed) }\end{array}$ \\
\hline Sex (male/female) & $\begin{array}{c}14 \mathrm{M} / \\
\mathrm{F}\end{array}$ & $18 \mathrm{M} / 30 \mathrm{~F}$ & $11 \mathrm{M} / 13 \mathrm{~F}$ & 0.094 & 0.386 \\
\hline Age (years) & $\begin{array}{c}66.1 \\
(10.3)\end{array}$ & $66.6(7.2)$ & $67.3(6.5)$ & 0.812 & 0.618 \\
\hline Height (m) & $\begin{array}{c}1.71 \\
(0.08)\end{array}$ & $1.69(0.09)$ & $1.69(0.09)$ & 0.324 & 0.495 \\
\hline Body mass (kg) & $\begin{array}{c}80.9 \\
(13.3)\end{array}$ & $71.6(12.5)$ & $73.0(10.2)$ & 0.005 & 0.026 \\
\hline BMI $\left(\mathrm{kg} / \mathrm{m}^{2}\right)$ & $27.5(3.2)$ & $25.1(4.0)$ & $25.6(4.1)$ & 0.011 & 0.077 \\
\hline \multirow{2}{*}{$\begin{array}{l}\text { Kellgren/Lawrence } \\
\text { (K/L) radiographic } \\
\text { severity scale }\end{array}$} & $\begin{array}{c}\text { Grade } 3: \\
11\end{array}$ & n.a. & n.a. & n.a. & n.a. \\
\hline & $\begin{array}{c}\text { Grade 4: } \\
13\end{array}$ & & & & \\
\hline HOOS Pain & $52.3(15.7)$ & $98.6(3.0)$ & $98.7(2.7)$ & $<0.001$ & $<0.001$ \\
\hline HOOS Symptoms & $48.3(16.5)$ & $97.3(4.7)$ & $96.5(5.4)$ & $<0.001$ & $<0.001$ \\
\hline HOOS ADL & $53.8(18.7)$ & $98.6(3.5)$ & $98.9(2.3)$ & $<0.001$ & $<0.001$ \\
\hline HOOS Sport/Rec & $35.1(24.3)$ & $98.0(5.0)$ & $98.2(3.4)$ & $<0.001$ & $<0.001$ \\
\hline HOOS QOL & $27.2(15.6)$ & $97.1(7.6)$ & $97.9(6.8)$ & $<0.001$ & $<0.001$ \\
\hline
\end{tabular}

This article is protected by copyright. All rights reserved. 
BMI - body mass index; HOOS - hip injury and osteoarthritis outcome score; ADL activities of daily living; Rec - recreation; QOL - quality of life.

Table 3. Mean (1 standard deviation) spatiotemporal gait parameters: trials of patients with hip OA scheduled for total hip replacement $(\mathrm{N}=24)$, trials of age-matched asymptomatic control subjects $(\mathrm{N}=48)$ and speed-matched selection of trials out of the group of control asymptomatic subjects $(\mathrm{N}=24)$.

\begin{tabular}{|c|c|c|c|c|c|c|c|}
\hline Parameter & $\begin{array}{l}\text { Patients } \\
N=24\end{array}$ & $\begin{array}{l}\text { Asymptomatic } \\
\text { controls } \\
\quad N=48\end{array}$ & $\begin{array}{c}\text { Subgroup } \\
\text { matched } \\
\text { speed } \\
N=24\end{array}$ & $\begin{array}{l}\text { 95\% CI } \\
\text { (patient- } \\
\text { controls) }\end{array}$ & $\begin{array}{l}\text { 95\% CI } \\
\text { (patient- } \\
\text { subgroup } \\
\text { matched } \\
\text { speed) }\end{array}$ & $\begin{array}{l}\text { P value } \\
\text { (patient- } \\
\text { controls) }\end{array}$ & $\begin{array}{l}\text { P value } \\
\text { (patient- } \\
\text { subgroup } \\
\text { matched } \\
\text { speed) }\end{array}$ \\
\hline $\begin{array}{l}\text { Stride duration } \\
\text { (s) }\end{array}$ & $\begin{array}{c}1.13 \\
(0.14)\end{array}$ & $1.07(0.08)$ & $\begin{array}{c}1.19 \\
(0.16)\end{array}$ & $\begin{array}{l}{[0.01 ;} \\
0.11]\end{array}$ & $\begin{array}{c}{[-0.14} \\
0.03]\end{array}$ & 0.030 & 0.183 \\
\hline $\begin{array}{l}\text { Stride length } \\
\text { (m) }\end{array}$ & $\begin{array}{c}1.17 \\
(0.18)\end{array}$ & $1.33(0.13)$ & $\begin{array}{c}1.24 \\
(0.15)\end{array}$ & $\begin{array}{c}{[-0.24 ;-} \\
0.09]\end{array}$ & $\begin{array}{c}{[-0.17 ;} \\
0.02]\end{array}$ & $<0.001$ & 0.121 \\
\hline $\begin{array}{l}\text { Walking speed } \\
(\mathrm{m} / \mathrm{s})\end{array}$ & $\begin{array}{c}1.05 \\
(0.21)\end{array}$ & $1.25(0.16)$ & $\begin{array}{c}1.06 \\
(0.18)\end{array}$ & $\begin{array}{c}{[-0.28 ;-} \\
0.10]\end{array}$ & $\begin{array}{c}{[-0.13} \\
0.11]\end{array}$ & $<0.001$ & 0.875 \\
\hline $\begin{array}{l}\text { Cadence } \\
\text { (steps/min) }\end{array}$ & $\begin{array}{l}107.6 \\
(12.0)\end{array}$ & $112.6(8.8)$ & $\begin{array}{r}102.5 \\
(11.4)\end{array}$ & $\begin{array}{l}\text { [-10.0; - } \\
\quad 0.1]\end{array}$ & $\begin{array}{l}{[-1.7 ;} \\
11.9]\end{array}$ & 0.048 & 0.141 \\
\hline $\begin{array}{l}\text { Stance phase } \\
\text { (\%gc) }\end{array}$ & $\begin{array}{r}63.3 \\
(2.6)\end{array}$ & $62.3(2.0)$ & $\begin{array}{r}63.3 \\
(2.1)\end{array}$ & $\begin{array}{c}{[-0.1 ;} \\
2.1]\end{array}$ & $\begin{array}{l}{[-1.3 ;} \\
1.4]\end{array}$ & 0.082 & 0.974 \\
\hline $\begin{array}{l}\text { Swing phase } \\
\text { (\%gc) }\end{array}$ & $\begin{array}{l}36.7 \\
(2.6)\end{array}$ & $37.7(2.0)$ & $\begin{array}{r}36.7 \\
(2.1)\end{array}$ & $\begin{array}{c}{[-2.1 ;} \\
0.1]\end{array}$ & $\begin{array}{c}{[-1.4 ;} \\
1.3]\end{array}$ & 0.082 & 0.974 \\
\hline $\begin{array}{l}\text { Single support } \\
\text { phase (\%gc) }\end{array}$ & $\begin{array}{l}34.7 \\
(4.6)\end{array}$ & 37.7 (1.7) & $\begin{array}{l}36.5 \\
(2.3)\end{array}$ & $\begin{array}{l}\text { [-4.5; - } \\
1.5]\end{array}$ & $\begin{array}{c}{[-3.9} \\
0.3]\end{array}$ & $<0.001$ & 0.090 \\
\hline $\begin{array}{l}\text { Double } \\
\text { support phase } \\
\text { (\%gc) }\end{array}$ & $\begin{array}{c}17.2 \\
(12.2)\end{array}$ & $12.4(1.6)$ & $\begin{array}{l}13.6 \\
(1.9)\end{array}$ & $\begin{array}{l}{[1.1 ;} \\
8.4]\end{array}$ & $\begin{array}{l}{[-1.5 ;} \\
8.6]\end{array}$ & 0.012 & 0.167 \\
\hline
\end{tabular}

CI—confidence interval, gc—gait cycle

This article is protected by copyright. All rights reserved. 